\title{
Determinants of the Job Burnout in Public Sector Employees in Malaysia
}

\author{
Vinod Boonratana ${ }^{1} \&$ Behrooz Gharleghi ${ }^{1}$ \\ ${ }^{1}$ Asia Pacific University of Technology and Innovation, Malaysia \\ Correspondence: Behrooz Gharleghi, Asia Pacific University of Technology and Innovation, Malaysia. E-mail: \\ gharleghi.bn@gmail.com
}

Received: March 10, 2015

Accepted: May 16, 2015

Online Published: May 22, 2015

doi:10.5539/ijbm.v10n6p208

URL: http://dx.doi.org/10.5539/ijbm.v10n6p208

\begin{abstract}
This study analyses the level of emotional exhaustion (EE), depersonalization (DP), and personal accomplishment (PA) towards job burnout (JB). Consequently, the relationship between the emotional exhaustion, depersonalization and personal accomplishment with job burnout were determined. The research is conducted with 151 respondents whom are the employees of Royal Malaysian Police (RMP), located at Bukit Aman - Kuala Lumpur in which the findings revealed that emotional exhaustion and depersonalization has a significant relationship with job burnout, while personal accomplishment does not.
\end{abstract}

Keywords: emotional exhaustion, depersonalization, personal accomplishment, job burnout

\section{Introduction}

Employees are known as an essential and important resource in any organisation, especially in organisations where manpower and performance are the core of the organisation's effectiveness. Understanding the cause of decrease in employee's productivity is important for business effectiveness as it enable organizations to detect, prevent and counter the problem. One of the factors in employee's productivity is job burnout, which is the main focus of this study. This study investigates the job burnout among the employees in the public sector. Royal Malaysian Police (RMP) employees are selected as the sample of study of the job burnout.

Formed in 1807, Royal Malaysian Police (RMP) is a part of security forces structure in Malaysia. The force is a centralised organisation with responsibilities ranging from traffic control to intelligence gathering (Boonratana, 2014). The headquarters is based in Bukit Aman which is the location of research and questionnaire distribution conducted. The purpose of this study is to examine the perceived level of burnout among the employees (respondents) of RMP and the relationship between emotional exhaustion, depersonalisation and personal accomplishment towards the burnout.

Even though burnout has a negative effect on the job turnover (Golembiewski et al., 1987), burnout is generally overlooked by management in companies of all sizes. The conventional wisdom views burnout as an “individual's problem” or a person's ineptness for not coping with the job, its stressors and demands (Pines and Aronson, 1988). Maslach and Jackson (1981) originally categorised burnout from the psychological perspective of those working in the human service field and operationalized with three dimensions. Thus, what is the level of emotional exhaustion, depersonalisation, personal accomplishment and job burnout among public sector employees?

Maslach and Jackson (1981) noted that the three components are inter-dependent upon each other. The first component, emotional exhaustion is defined as feeling overwhelmed and emotionally drained. The second component, depersonalisation is defined and characterised as withdrawing from others and becoming negative. Lastly, reduced personal accomplishment is described as a feeling that one's work is not successfully achieved or by feeling of a lack of accomplishment. Therefore, is there any correlation between the job burnout and emotional exhaustion, depersonalization and personal accomplishment? Based on this objective, following hypotheses can be formed:

Hypothesis 1: H0: There is no significant relationship between Job Burnout and Emotional Exhaustion.

Hypothesis 2: H0: There is no significant relationship between Job Burnout and Depersonalization. 
Hypothesis 3: H0: There is no significant relationship between Job Burnout and Personal Accomplishment.

\section{Literature Review}

\subsection{Emotional Exhaustion}

Emotional Exhaustion (EE) occurs when there is an overwhelming demand on one's time and energy. EE is known as a core dimension of burnout (Gaines \& Jermier, 1983) as well as a "state caused by psychological and emotional demands made on people" (Bacharach et al., 1991). Since EE is conceptualised as the first stage of burnout (Maslach \& Jackson, 1981), EE is important as it is a point of possible managerial intervention in the burnout process.

Maslach and Jackson (1986) identified emotional exhaustion as the most critical aspect among the dimension. Employees whom encounters emotional exhaustion feels overextended and overworked, where one dreads coming to work and faces lack of energy to face another day at the job (Maslach \& Leiter, 1997). In this condition, frustration and hopelessness takes over as the demand of the job continues to outperform the employee's capability (Pines \& Aronson, 1988).

According to Cropanzano et al. (2003) and Westman and Eden (1997), EE is one of the factors that encourage employees to be more likely to withdraw form an organisation. As a support to this view, meta-analytic findings and reviews reveal that emotional exhaustion is consistently positively related to turnover intentions and actual turnover (Swider \& Zimmerman, 2010). When an individual is exhausted, one's personal resources are spent and as a consequence, on engage in withdrawal and avoidant coping strategies to protect themselves from further damages to their health (Halbesleben, 2006).

\subsection{Depersonalization}

Depersonalization (DP) emerges as a mean of defending oneself once one experience EE. Withdrawing from job, no care towards clients or programs and becoming cynical with management and other staffs are characteristics of employees whom experiencing DP (Maslach \& Jackson, 1981). The "I do not care" attitude exists as the dimension detaches the individual from his or her job. At this point, the employee exhibits negative behaviours towards clients, employees and management. Campbell et al. (2013) studies states that individuals use withdrawal-based coping mechanisms as the face resource loss and subsequent burnout which is the one way individual use to preserve the remaining resources such as commitment to organisation.

Also known as cynicism, DP appears to be the most problematic. Maslach (1982) described DP as a "detached, callous, and even dehumanised response" to clients. Also, cynical employees are likely to be less loyal to their employer as their negative attitudes increase. Acting as a defensive mechanism, DP arises when the shield of detachment is truly thick that no feelings and emotions able to penetrate through. When detachment increases, the attitude of cold indifference to others' needs and a callous disregard for their feelings occur. The individual may derogate other people and put them down, uncivilised and lose the sense of courtesy, ignoring others pleas and demands or fail to provide appropriate help, care and service. Cherniss (1980) described a similar condition which includes withdrawal, hostility and indifference toward others as "dehumanisation".

With the development of Maslach Burnout Inventory-General Survey (Maslach et al., 1996), Cherniss, 1980 and Pines et al. (1981) argues that dehumanisation as being intrinsic to burnout, as it is concentrated solely on human services occupation only. However, DP is still a valid dimension in Maslach Burnout Inventory and widely used to measure burnout as well as quoted by other researchers as the basis for their own research and writing (Shinn, 1982).

\subsection{Personal Accomplishment}

Personal accomplishment (PA) is reduced as EE and DP takes place, where employees will experience a reduction in the sense of personal achievement which includes evaluating oneself negatively to a point where he or she doubts the contribution and capabilities of their work (Sethi et al., 1999). There are many contributors towards reduced PA. For example, when there is a lack of employee involvement in the decision-making process, an employee will experience less valued and not being a part of the team.

Eccles et al. (1983) defined different components of achievement values, namely attainment value, intrinsic value, utility value and cost value. Attainment values are the importance of doing well on a given job. Intrinsic value refers to the enjoyment on gains from doing the task (Harter, 1981). Utility value are the extent how the task fits into an individual future plans. Lastly, cost refers to how the decision to involve in one activity limits access to other activities or in other word, sacrifice of an individual in order to accomplish a task. Therefore, individual with lack of PA would be experiencing low attainment value, intrinsic value, utility value and cost 
value when involving in a task.

Theorist of expectancy-value theory argue that individuals' belief on how well they will do on an activity and to which extent they value the activity are able to explain one's choice, persistence and performance (Eccles et al., 1983; Wigfield, 1994; Wigfield \& Eccles, 1992). PA as an ability-related belief, are measured in different ways. Bandura (1997) argued that efficacy should be measured specifically as specific measures of belief relate much more closely to behaviour. On the other hand, Pajares (1996) noted that efficacy most often has been measured at the task-specific level.

\subsection{Job Burnout}

The term "burnout" was first created by Freudenberger (1974) to characterise a situation experience by human service professionals who appear to be exhausted or up to a state of inability to perform their tasks effectively or sometimes to even care for their clients. Maslach (1976) defined burnout as a condition in which one loses all concerns, feeling towards the person one works with and comes to treat them as impersonal objects.

Burnout has a negative effect on the individual's performance in the workplace, and it has been related to absenteeism, job turnover, low productivity, overall effectiveness, decrease in job satisfaction, and reduced commitment to the job (Golembiewski et al., 1987). According to Leiter and Maslach (1988) there is a sequential progression to the three phases of burnout. They argued that the first stage, exhaustion, leads to cynicism, which in turn leads to inefficacy. Although more research is needed, Burke and Greenglass's (2001) research showed that apart from negative effects in work, burnout might have negative effect on people's home life.

Although burnout has been conceptualised as a three dimension syndrome, several researchers agrees that EE is the essential component of burnout (Rohland et al., 2004). The other two dimensions, DP and PA are regarded as different but theoretically related variables, which accompany EE (Shirom \& Ezrachi, 2003). Furthermore, previous studies showed that EE could predict DP and PA (Lee \& Ashforth, 1993).

The model employed in this study derived from Tsigilis et al. (2006) who used Employee Satisfaction Inventory (ESI) and Maslach's Burnout Inventory (MBI, Maslach \& Jackson, 1986) to conduct a comparison between public and private sector employees on job satisfaction and burnout among Greek early educators. In this paper, the dependent variable is job satisfaction and burnout while the independent variable refers to "emotional exhaustion", "working conditions", "pay", "promotion", "job itself", "immediate supervisor" and the "organisation as a whole". According to Tsigilis study, it is well established that a consequence of burnout syndrome is turnover (Maslach \& Leiter, 1999). This study aims to examine perceived levels of burnout of Malaysian royal Police as a public sector.

\subsection{Research Framework}

Based on the literature review given towards the independent variables and dependent variable, the following framework can be given and it will be examined in this study.

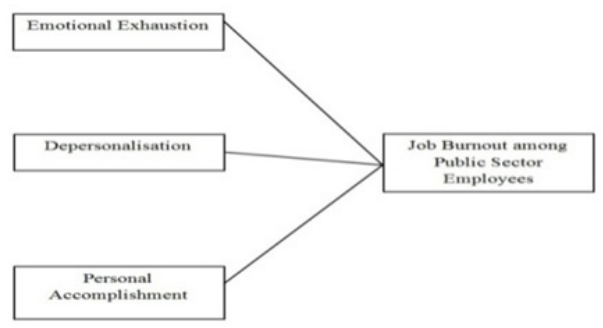

Figure 1. Research framework

\section{Methodology}

\subsection{Research Design and Sampling Methodology}

This is a quantitative study. In terms of objectives, this is a correlational study. Looking into the sampling methodology, the population in this study is RMP employees in Malaysia. The sample in this study refers RMP employees in Bukit Aman-Kuala Lumpur. In term of sampling methodology, this study had used quota sampling methodology.

The total number of 151 respondents details are keyed into SPSS one by one and the individual data will be 
analysed on a group basis in order to obtain the findings from questionnaires. Graphical presentation such as pie charts, bar charts and scatter plot graphs are used to ease the interpretation work. By analysing the frequencies of these variables helps to better construe the relevancy and validity of the sample group within this research. In this research paper, the statistic will include the descriptive statistics. This study employed the Pearson Moment Correlation test as well as regression to examine the relationship between variables.

\section{Findings}

\subsection{Demographics of Sample}

This section depicts the demographics of the sample. The tables and pie charts below illustrates the demographics of the participants who responded to the survey in percentages.

Table 1. Sample demographics: percentage of responses by gender

\begin{tabular}{llllll}
\hline & Sum of Squares & Frequency & Percent & Valid percent & Cumulative percent \\
\hline valid & Male & 108 & 71.5 & 71.5 & 71.5 \\
& Female & 43 & 28.5 & 28.5 & 100.0 \\
& Total & 151 & 100.0 & 100.0 & \\
\hline
\end{tabular}

\subsection{Descriptive Statistics}

According to Knowledge Base, descriptive statistics are "used to describe the basic features of the data in a study". Descriptive statistics simply describes what the data is, what does it shows and used to present quantitative descriptions in a manageable form. The tables and bar charts below illustrates the descriptive statistics of this study.

Table 2. Descriptive statistics: overall statistics

\begin{tabular}{llllll}
\hline & $\mathrm{N}$ & Minimum & Maximum & Mean & Std deviation \\
\hline Job Burnout & 151 & 0 & 19 & 8.25 & 4.90 \\
Emotional Exhaustion & 151 & 0 & 19 & 7.05 & 4.56 \\
Depersonalisation & 151 & 0 & 18 & 8.64 & 4.32 \\
Personal accomplishment & 151 & 0 & 17 & 6.59 & 4.55 \\
Valid N & 151 & & & & \\
\hline
\end{tabular}

\subsection{ANOVA Test}

Analysis of Variance (ANOVA) is used in the statistical test which determines the existence of significant differences between the means of three independent variables (Laerd Statistics, 2013). The table below illustrates the ANOVA of emotional exhaustion, depersonalisation and personal accomplishment.

Table 3. ANOVA analysis

\begin{tabular}{llllll}
\hline ANOVA $^{\mathrm{a}}$ & Sum of Squares & $\mathrm{df}$ & Mean Square & F & Sig. \\
\hline Regression & 1985.17 & 3 & 661.72 & 59.70 & $0.000^{\mathrm{b}}$ \\
Residuals & 1626.25 & 147 & 11.08 & & \\
Total & 3614.43 & 150 & & & \\
\hline
\end{tabular}

a. dependent Variable: Job Burnout.

b. predictors: (constant), PA, DP, EE.

The significance level is $.000(\mathrm{p}=.000 ; \mathrm{p}<.05)$. Therefore, there is a statistically significant difference determined by ANOVA in the means of emotional exhaustion, depersonalisation, personal accomplishment and 
job burnout.

\subsection{Correlation Results}

Table 4 represent the correlation results between the Job Burnout and independent variables which are Emotional Exhaustion (EE), Depersonalization (DP), Personal Accomplishment (PA).

Table 4. Correlation results

\begin{tabular}{lllll}
\hline & EE & DP & PA \\
\hline JB & Pearson Correlation & 0.721 & 0.491 & 0.195 \\
& Sig. (2-tailed) & .000 & .000 & .017 \\
& $\mathrm{~N}$ & 151 & 151 & 151 \\
\hline
\end{tabular}

Note. Emotional Exhaustion (EE), Depersonalization (DP), Personal Accomplishment (PA), Job Burnout (JB).

The Pearson's R for the correlation between job burnout and emotional exhaustion is .721. As Pearson's R is positive and close to 1, the relationship is positive and strongly correlated. Since the Sig (2-tailed) is .000 which is less than .05 , there is a statistically significant correlations between job burnout and emotional exhaustion.

The Pearson's R for the correlation between job burnout and depersonalisation is .491. As Pearson's R is positive and close to 0.5 , the relationship is positive and moderately correlated. Since the Sig (2-tailed) is .000 which is less than .05 , there is a statistically significant correlations between job burnout and depersonalisation.

The Pearson's R for the correlation between job burnout and personal accomplishment is .195. As Pearson's R is positive and close to 0 , the relationship is positive and weakly correlated. Since the Sig (2-tailed) is .017 which is less than .05 , there is a statistically significant correlations between job burnout and personal accomplishment. Since the main aim of this paper is to proceed with hypotheses testing, therefore we applied the regression analysis as the result of correlation test is not appropriate for this purpose. In addition the advantage of regression over correlation is that, in the former all the variables can be included in the model together, while in the latter not. To do so, following tables are provided and indicate the model summary and coefficient values.

\subsection{Model Summary}

Table 5. Model summary, regression

\begin{tabular}{lllll}
\hline Model & $\mathrm{R}$ & R Square & Adjusted R Square & $\begin{array}{l}\text { Std. Estimat of the } \\
\text { Estimate }\end{array}$ \\
\hline 1 & $.741^{\mathrm{a}}$ & .549 & .540 & 3.329 \\
\hline
\end{tabular}

a. predictors: (constant), PA, DP, EE.

The value of R Square is .549 which means that 54.9 percent of the variations in job burnout has been explained by independent variables chosen in this study. Following table provides the regression results.

Table 6. Regression coefficients

\begin{tabular}{|c|c|c|c|c|c|c|}
\hline & & $\begin{array}{l}\text { Unstandardized } \\
\text { coefficients }\end{array}$ & & $\begin{array}{l}\text { standardized } \\
\text { coefficients }\end{array}$ & & \\
\hline & & Beta & Std. error & Beta & t-stat & Sig. \\
\hline \multirow[t]{4}{*}{1} & Constant & 2.260 & 0.670 & & 3.372 & 0.001 \\
\hline & $\mathrm{EE}$ & 0.729 & 0.074 & 0.678 & 9.912 & 0.000 \\
\hline & DP & 0.189 & 0.073 & 0.166 & 2.569 & 0.011 \\
\hline & $\mathrm{PA}$ & -0.118 & 0.065 & -0.110 & -1.818 & 0.071 \\
\hline
\end{tabular}

Dependent variable: Job Burnout. 
The regression result revealed that there is a positive relationship between EE, DP with Job Burnout, while the relationship between PA and JB is negative. Furthermore, the significance level shows that the relationship between EE, DP is significant at 5\% level. While the significance level of PA is above $5 \%$ and it has no significant effect towards JB. But if we consider $10 \%$ for level of significance, then all variables are considered to have an effect toward JB. Following is the hypotheses testing using regression results:

Hypothesis 1: H0: There is no significant relationship between Job Burnout and Emotional Exhaustion;

The coefficient value for this variable in table 6 shows that there is significant relationship between Job Burnout and Emotional Exhaustion $(\mathrm{p}=.000)$. Therefore, the null hypothesis is rejected.

Hypothesis 2: H0: There is no significant relationship between Job Burnout and Depersonalisation;

The coefficient value for this variable in table 6 shows that there is significant relationship between Job Burnout and Depersonalisation $(\mathrm{p}=.011)$. Therefore, the null hypothesis is rejected.

Hypothesis 3: H0: There is no significant relationship between Job Burnout and Personal Accomplishment;

The coefficient value for this variable in table 6 shows that there is no significant relationship between Job Burnout Personal Accomplishment $(\mathrm{p}=.071)$. Therefore, the null hypothesis is accepted.

\section{Conclusion}

There were three hypotheses that were tested in the study. The first hypothesis tested the significant relationship between job burnout and emotional exhaustion. Results for the first hypothesis indicated a positive and significant relationship between job burnout and emotional exhaustion. The linear relationship showed a coefficient correlation of .729 and probability of .000 which is less than .05 . The second hypothesis tested the significant relationship between job burnout and depersonalisation. Results for the second hypothesis indicated a positive and significant relationship between job burnout and Depersonalization. The linear relationship showed a coefficient of .189 and probability of .011 which is level less than .05 . The third hypothesis tested the significant relationship between job burnout and personal accomplishment. Results for the third hypothesis indicated a negative but not significant relationship between job burnout and personal accomplishment. The relationship showed a coefficient of -.118 and probability of .071 which is greater than .05 . Based on the result showed, the emotional exhaustion and depersonalisation have significant relationship with job burnout in most of the ways. However, there was no significant relationship shown between job burnout and personal accomplishment. The objectives of the research are fulfilled with the result acceptance. Since job burnout analysis is one of many ways to evaluate business effectiveness, the research tends to provide evidence to support future research related to this field.

\subsection{Recommendation and Suggestions}

Based on the findings of this study, there are some inconsistencies in the measurement of burnout. Although Maslach Burnout Inventory - General Survey is widely used by researchers, the score and analyse is inconsistent. As a recommendation, full Maslach Burnout Inventory with frequency ratings only, reporting descriptive statistics on all three subscales, reporting all predictors with all three subscales and reporting the third scale as personal accomplishment, not as reduced personal accomplishment can be used. The recommendation may save the discipline from many complicated sentences. There remains considerable work to be done in integrating the range of perspectives on burnout among public sector employees. Structural equation model will likely play an important role because of its capacity to capture the complexity of the phenomenon. As indicated by Maslach et al (1996) the research that puts burnout research into the context of psychological theory holds the most promise for understanding the burnout process and developing interventions to prevent or alleviate it.

\section{References}

Bacharach, S. B., Bamberger, P., \& Conely, S. (1991). Work-Home Conflict among Nurses and Engineer: Mediating the Impact of Stress on Burnout and Satisfaction at Work. Journal of Organizational Behaviour, 12, 39-63. http://dx.doi.org/10.1002/job.4030120104

Bandura, A. (1997). Self-efficacy: The exercise of control. New York: W. H. Freeman.

Boonratana, C. (2014). Assistant Commissioner of Police, Royal Malaysian Police. Kuala Lumpur.

Burke, R. J., \& Greenglass, E. R. (2001). Hospital restructuring, work-family conflict and psychological burnout among nursing staff. Psychological Health, 22, 123-132. http://dx.doi.org/10.1080/08870440108405528

Campbell, N. S., Perry, S. J., Maertz, C. P., Allen, D. G., \& Griffeth, R. W. (2013). All you need is ... resources: The effects of justice and support on burnout and turnover. Human Relations, 66(6), 759-782. 
http://dx.doi.org/10.1177/0018726712462614

Cherniss, C. (1980). Staff burnout: Job stress and the human services. Beverly Hills: Sage Publications.

Cropanzano, R., Rupp, D. E., \& Byrne, Z. S. (2003). The relationship of emotional exhaustion to wok attitudes, job performance, and organizational citizenship behaviours. Journal of Applied Psychology, 88, 160-169. http://dx.doi.org/10.1037/0021-9010.88.1.160

Eccles, J. S., Adler, T. F., Futterman, R., Goff, S. B., Kaczala, C. M., Meece, J. L., \& Midgley, C. (1983) Expectancies, values, and academic behaviours: Achievement an achievement motivation. San Francisco: W. H. Freeman.

Edrak B., Chan, B. Y. F., Gharleghi, B., \& Thiam, K. S. (2013). The effectiveness of intrinsic and extrinsic motivations: A study of Malaysian Amway company's direct sales forces. International Journal of Business and Social Science, 4(9), 96-103.

Freudenberger, H. J. (1974). Staff Burn-out. Journal of Social Issues, 30, 159-165. http://dx.doi.org/10.1111/j.1540-4560.1974.tb00706.x

Gaines, J., \& Jernier, J. M. (1983). Emotional Exhaustion in a High Stress Environment. Academy of Management Journal, 26, 667-686. http://dx.doi.org/10.2307/255907

Golembiewski, R. T., Hilles, R., \& Daly, R. (1987). Some effects on OD interventions on burnout and worksites $\begin{array}{lllll}\text { features. Journal of Applied Behavioural } & \text { Science, 23, }\end{array}$ http://dx.doi.org/10.1177/002188638702300302

Halbesleben, J. R. B. (2006). Sources of social support and burnout: A meta-analytic test of the conservation of resources model. Journal of Applied Psychology, 91(5), 1340-1145. http://dx.doi.org/10.1037/0021-9010.91.5.1134

Harter, S. (1981). A new self-report scale of intrinsic versus extrinsic orientation in the classroom: Motivational and informational components. Developmental Psychology, 17, 300-312. http://dx.doi.org/10.1037/0012-1649.17.3.300

Laerd Statistics. (2003). One-way ANOVA. Retrieved from https://statistics.laerd.com/statistical-guides/one-way-anova-statistical-guide.php

Lee, R. T., \& Ashforth, B. E. (1993). A further examination of managerial burnout: Toward an intergraded model. Journal of Organizational Behaviour, 14(1), 3-20. http://dx.doi.org/10.1002/job.4030140103

Leiter, M. P., \& Maslach, C. (1988). The impact of interpersonal environment on burnout and organizational $\begin{array}{llll}\text { commitment. Journal of } & \text { Organizational }\end{array}$ http://dx.doi.org/10.1002/job.4030090402

Maslach, C. (1976). Burn-out. Human Behaviour, 5, 7-22.

Maslach, C. (1982). Burnout-The cost of caring. Englewood Cliffs, New Jersey: Prentice Hall.

Maslach, C., \& Jackson, S. E. (1981). The measurement of experienced burnout. Journal of Occupational Behaviour, 2, 99-113. http://dx.doi.org/10.1002/job.4030020205

Maslach, C., \& Jackson, S. E. (1986). Maslach burnout inventory manual. Palo Alto: Consulting Psychologists Press.

Maslach, C., \& Leiter, M. P. (1997). The truth about: How organizations cause personal stress and what to do about it. San Francisco: Jossey-Bass.

Maslach, C., \& Leiter, M. P. (1999). Teacher burnout: A research agenda. In R. Vandenberghe \& A. M. Huberman (Eds.), Understanding and preventing teacher burnout: A sourcebook of international research and practice (pp. 295-303). Cambridge: Cambridge University Press. http://dx.doi.org/10.1017/CBO9780511527784.021

Maslach, C., Jackson, S. E., \& Leiter, M. P. (1996). Maslach burnout inventory manual (3rd ed.). CA: Consulting Psychologists Press.

Pajares, F. (1996). Self-efficacy beliefs in academic settings. Review of Educational Research, 66, 543-578. http://dx.doi.org/10.3102/00346543066004543

Pines, A., \& Aronson, E. (1988). Career burnout causes and cures. London: MacMillan.

Pines, A., Aronson, E., \& Kafry, D. (1981). Burnout: From tedium to personal growth. New York: Free Press. 
Rohland, B. M., Kruse, G. R., \& Rohrer, J. E. (2004). Validation of a single-item measure of burnout against the Maslach Burnout Inventory among physicians. Stress and Health, 20(2), 75-79. http://dx.doi.org/10.1002/smi.1002

Sethi, V., Barrier, T., \& King, K. (1999). An examination of the correlates of burnout in information systems professionals. Information Resources Management Journal, 12(3), 5-13. http://dx.doi.org/10.4018/irmj.1999070101

Shinn, M. (1982). Methodological issues: Evaluating and using information. Job stress and burnout. Beverly Hills: Sage Publications.

Shirom, A., \& Ezrachi, Y. (2003). On the discriminant validity of burnout, depression and anxiety: A re-examination of the burnout measure. Anxiety, Stress and Coping, 16(1), 83-97. http://dx.doi.org/10.1080/1061580021000057059

Swider, B. W., \& Zimmerman, R. D. (2010). Born to burnout: A meta-analytic path model of personality, job burnout and work outcomes. Journal of Vocational Behaviour, 76(3), 487-506. http://dx.doi.org/10.1016/j.jvb.2010.01.003

Trading Economics. (2014). Malaysian Economics Indicator. Retrieved from http://www.tradingeconomics.com/malaysia/indicators

Tsigilis, N., Zachopoulou, E., \& Grammatikopoulos, V. (2006). Job satisfaction and burnout among Greek early educators: A comparison between public and private sector employees. Educational Research and Review, 1(8), 256-261.

Westman, M., \& Eden, D. (1997). Effects of a respite from work on burnout: Vacation relief and fade-out. Journal of Applied Psychology, 82, 516-27. http://dx.doi.org/10.1037/0021-9010.82.4.516

Wigfield, A. (1994). Expectancy-value theory of achievement motivation: A developmental perspective. Educational Psychology Review, 6, 49-78. http://dx.doi.org/10.1007/BF02209024

Wigfield, A., \& Eccles, J. (1992). The development of achievement task values: A theoretical analysis. Developmental Review, 12, 265-310. http://dx.doi.org/10.1016/0273-2297(92)90011-P

\section{Copyrights}

Copyright for this article is retained by the author(s), with first publication rights granted to the journal.

This is an open-access article distributed under the terms and conditions of the Creative Commons Attribution license (http://creativecommons.org/licenses/by/3.0/). 